\title{
INDICADORES DE QUALIDADE DO LEITE BOVINO ORGÂNICO EM DUAS PROPRIEDADES LEITEIRAS CERTIFICADAS DO ESTADO DE SÃO PAULO
}

\author{
A.K. Siqueira ${ }^{1 *}$, T. Salerno ${ }^{2 *}$, G.H.B. Lara ${ }^{2 *}$, L.A.Z. Condas ${ }^{2 * *}$, \\ F.J.P. Listoni ${ }^{2}$, A.C. Paes ${ }^{2}$, A.V. da Silva ${ }^{3}$, D. da S. Leite ${ }^{4}$, M.G. Ribeiro
}

${ }^{1}$ Universidade Estadual Paulista, Faculdade de Medicina Veterinária e Zootecnia, Departamento de Higiene Veterinária e Saúde Pública, Distrito de Rubião Junior, s/noㅡ, CEP 18618-970, Botucatu, SP, Brasil. E-mail: kellersiqueira@hotmail.com.

\section{RESUMO}

O presente estudo avaliou a composição química, a contagem bacteriana total, o nível de celularidade e presença de resíduos de antimicrobianos no leite de duas propriedades em sistema orgânico de produção do interior do Estado São Paulo com base na IN 062-MAPA. O leite da Propriedade I apresentou média de CCS de $7,13 \times 10^{5}$ céls / mL e o da Propriedade II 3,27 x $10^{5}$ céls/ $\mathrm{mL}$. As médias das CBTs foram de 7,80 × $10^{5}$ céls $/ \mathrm{mL}$ na Propriedade I e de $6,15 \times 10^{5}$ céls $/ \mathrm{mL}$ na Propriedade II. A propriedade I apresentou como média de gordura de 3,10\%, de proteína 3,26\% e 4,54\% de lactose, enquanto a Propriedade II apresentou 3,44\% de gordura, 3,39\% de proteína e $4,50 \%$ de lactose, nos 12 meses avaliados. A presença de resíduos de antimicrobianos foi detectada em seis amostras (6,97\%) da Propriedade I e em 16 (9,24\%) da Propriedade II. Os resultados obtidos revelam falha nos preceitos da produção orgânica.

PALAVRAS-CHAVE: Leite orgânico, qualidade do leite, mastite, resíduos de antimicrobianos, bovinos.

\section{ABSTRACT}

QUALITY INDICATORS OF ORGANIC BOVINE MILK IN TWO CERTIFIED DAIRY HERDS IN SÃO PAULO STATE, BRAZIL. This study evaluated the chemical composition, total bacterial count, the level of cellularity and presence of antimicrobial residues in milk from two small farms in organic production system in the state of São Paulo, Brazil, based in NI 062-MAPA. The milk of the Property I had the mean of CCS $7.13 \times 10^{5}$ cells $/ \mathrm{mL}$ and the Property II had $3.27 \times 10^{5}$ cells / $\mathrm{mL}$. The averages of CBT were, respectively, $7.80 \times 10^{5}$ cells $/ \mathrm{mL}$ in the Property I and $6.15 \times 10^{5}$ cells $/ \mathrm{mL}$ in Property II. The Property I presented as an average of $3.10 \%$ of fat, $3.26 \%$ of protein and $4.54 \%$ of lactose, while the Property II presented $3.44 \%$ of fat, $3.39 \%$ of protein and $4.50 \%$ of lactose in 12 months assessed. The presence of residues of antimicrobial drugs was detected in six samples (6.97\%) of the Property I and 16 (9.24\%) of Property II. The results obtained reveal failure in the percepts of organic production.

KEY WORDS: Organic milk, milk quality, mastitis, antimicrobial residues, bovine.

A produção e o consumo de leite e derivados vêm crescendo exponencialmente no Brasil. Em 2005 foram produzidos cerca de 24,5 bilhões de litros de leite no Brasil. Já em 2010, aproximadamente, 30,7 bilhões de litros de leite foram produzidos no País (IBGE, 2010).
Tem-se notado incremento significativo na procura por produtos e subprodutos de origem animal produzidos no sistema orgânico. Acreditase que o Brasil pode se tornar o maior exportador de produtos orgânicos do mundo (CAMPIOLO; SILVA, 2006).

${ }^{2}$ Universidade Estadual Paulista, Faculdade de Medicina Veterinária eZootecnia, Serviço de Diagnóstico Microbiológico, Laboratório de Microbiologia, Botucatu, SP, Brasil.

${ }^{3}$ Universidade Estadual de Feira de Santana, Departamento de Ciências Biológicas, Feira de Santana, BA, Brasil.

${ }^{4}$ UNICAMP, Instituto de Biologia, Departamento de Genética, Evolução e Bioagentes, Campinas, SP, Brasil.

*Doutorandos do Programa de Pós-graduação em Medicina Veterinária da Universidade Estadual Paulista, FMVZ/ UNESP, Botucatu, SP.

**Mestranda do Programa de Pós-graduação em Medicina Veterinária da Universidade Estadual Paulista, FMVZ/ UNESP, Botucatu, SP. 
A Federação Internacional dos Movimentos de Agricultura Orgânica (IFOAM) descreveu que em 2007 o Brasil possuía 1,7 milhões de hectares destinados à produção de orgânicos (IFOAM, 2009). Apesar de possuir grande extensão de terras reservadas para a agricultura orgânica, a produção de leite orgânico no Brasil é irrisória, não atingindo 0,01\% da produção nacional (IFOAM, 2003).

Em 18 de dezembro de 2008 o MAPA sancionou a IN 064. Desta forma, a produção orgânica nacional passa a ter critérios desde a exploração da propriedade rural até a comercialização, dando grande impulso ao setor, visto que a regulamentação e a criação de sistema de avaliação propiciam maior garantia aos consumidores e aumenta a credibilidade do produto (BRASIL, 2008).

Em virtude do aumento da procura por alimentos orgânicos, do consequente acréscimo na produção de leite orgânico no país e da escassez de estudos voltados à qualidade do produto comercializado, o presente estudo avaliou a composição química, a celularidade e a presença de resíduos de antimicrobianos de leite bovino produzido em duas propriedades orgânicas localizadas no leste e no centro-oeste paulista.

Ao longo de 12 meses foram realizadas 12 coletas de leite em duas propriedades de exploração leiteira, certificadas como orgânicas (ECOCERT..., 2011; IBD, 2011). As propriedades possuíam entre 10 e 45 animais em lactação, em regime de duas ordenhas mecânicas diárias do tipo "balde ao pé", com utilização de mão-de-obra familiar.

Foram colhidas amostras de leite de 178 animais (259 tetos), após antissepsia dos tetos com álcool $70 \%$, além de 63 amostras de latões. O diagnóstico da mastite clínica foi baseado em alterações macroscópicas do leite (sangue, grumos e pus) na prova da caneca telada de fundo escuro e na presença de inflamação na glândula mamária (RADOSTiTs et al., 2007). A mastite subclínica foi diagnosticada utilizando o teste clássico de California Mastitis Test (CMT) (SCHALm et al.,1971). Os quartos mamários que apresentaram escores $2+$ ou 3+ no CMT foram considerados com mastite subclínica.

Alíquotas das amostras foram encaminhadas para o Laboratório de Controle da Qualidade do Leite, ESALQ-USP/Piracicaba, SP, para avaliação da composição química (gordura, proteína, lactose, extrato seco total e extrato seco desengordurado) pela técnica de infravermelho e quantificação da contagem de células somáticas (CCS) e contagem bacteriana total (CBT) utilizando-se citometria de fluxo, em frascos próprios com conservantes específicos fornecidos pelo Laboratório.

A detecção de resíduos foi realizada com o kit comercial Delvotest ${ }^{\circledR}$ (DSM Food Specialties Dairy Ingredients, The Netherlands), conforme as reco- mendações do fabricante, a partir de alíquotas das amostras de leite.

Foi observada mastite clínica em dois animais $(1,1 \%)$, sendo um de cada propriedade. Já a forma subclínica foi diagnosticada em 34,8\% (62/178) dos animais, 27,4\% (17/62) da Propriedade I e 72,6\% (45/62) da Propriedade II. De maneira similar, RIBEIRO et al. (2009) encontraram frequência de 1,3\% de mastite clínica em animais provenientes de quatro propriedades leiteiras certificadas como orgânicas do interior do Estado de São Paulo e 49,3\% com mastite subclínica. ElLis et al. (2007) também observaram baixas taxas de mastite clínica nos rebanhos orgânicos na Inglaterra, aproximadamente, 3,5\% das vacas. Em contraste, WELLER; BowLING (2000), também na Inglaterra, ao avaliarem 10 rebanhos orgânicos encontraram $34,7 \%$ de prevalência da mastite clínica.

Os resultados obtidos no presente estudo revelaram maior ocorrência da mastite subclínica, fato que pode ser justificado pelo predomínio de microorganismos contagiosos nas infecções mamárias em vacas nos sistemas de criação orgânico, intimamente relacionados ao estabelecimento de infecções subclínicas (RibeIro et al., 2009).

Segundoa Instrução Normativa 062 (BRASIL, 2011), oleite de qualidade para o consumidor deveconter no mínimo 3\% de gordura, 8,4\% de sólidos desengordurados e $2,9 \%$ de proteína. CCS não pode ultrapassar $6,0 \times 10^{5}$ células /mL e CBT 6,0 × $10^{5} \mathrm{UFC} / \mathrm{mL}$.

FERNANDEZetal. (2009) avaliaram o leite ecológico produzido em unidade de produção do Rio Grande do Sul e verificaram 3,14\% de gordura, 9,3\% de sólidos desengordurados e 3,19\% de proteína, valores muito semelhantes aos encontrados nas duas propriedades amostradas do interior do Estado de São Paulo. As pequenas variações na composição podem ser reflexo de diferenças raciais, fase de lactação dos animais, idade, além de condições de manejo, principalmente nutricional (COMERON et al., 2005). Porém, no mesmo estudo, os pesquisadores encontraram média de CCS acima de 1,2 × $10^{6}$ células/mL, valor superior aos 7,13 $\times 10^{5}$ obtidos na Propriedade Ie $3,2 \times 10^{5}$ células/ $\mathrm{mL}$ da Propriedade II amostradas no presente estudo.

Ribeiro et al. (2009) e LANGONi et al. (2009) investigaram as contagens celulares de leite proveniente de propriedades orgânicas no Brasil e observaram valores inferiores a 4,0 × $10^{5}$ células/ $\mathrm{mL}$ em animais com ou sem mastite. Estes achados estão em consonância com o observado na Propriedade II desta pesquisa. No intuito de mensurar parâmetros de qualidade do leite orgânico e convencional produzidos no interior deSão Paulo, CAMPOS (2004) encontrou, respectivamente, $1,7 \times 10^{6}$ células/ $\mathrm{mL}$ e 3,4 × $10^{5}$ células/mL. De acordo com os parâmetros estabelecidos na IN 062 (BRASIL, 2011), 
Indicadores de qualidade do leite bovino orgânico em duas propriedades leiteiras certificadas do Estado de São Paulo.

que atualmente aceita na plataforma o leite com até $6,0 \times 10^{5}$ células $/ \mathrm{mL}$, o leite orgânico avaliado no presente estudo seria considerado impróprio para o consumo.

Na Suiça, RoEsch et al. (2007) encontraram média de $4,0 \times 10^{4}$ células/mL de CCS em propriedades de leite orgânico. Ellis et al. (2007) encontraram, aproximadamente, $2,0 \times 10^{5}$ células $/ \mathrm{mL}$ em fazendas orgânicas da Inglaterra. No entanto, na Suécia, HAMILTON et al. (2006) constataram valores de CCS variando entre $8,3 \times 10^{4}$ células/mLe2,8 $810^{5}$ células/ $\mathrm{mL}$. Ao compararem a composição de leite cru de propriedades orgânicas certificadas e convencionais da Suécia Toledo et al. (2002) demonstraram não haver diferenças estatísticas entre a qualidade do leite produzido nos dois sistemas.

A ocorrência de mastite também pode ser verificada pela CBT. De acordo com a IN 062, aceitam-se atualmente até $6,0 \times 10^{5} \mathrm{UFC} / \mathrm{mL}$ (BRASIL, 2011). $\mathrm{O}$ presente estudo encontrou médias acima do permitido nas duas propriedades. A Propriedade I apresentou 7,8 $\times 10^{5} \mathrm{UFC} / \mathrm{mL}$. A Propriedade II apresentou média dentro dos parâmetros de qualidade, 6,1 x 104 UFC/mL. LANGONi et al. (2009), em duas dentre três propriedades orgânicas avaliadas no interior do Estado de São Paulo, encontraram 8,5 x $10^{5} \mathrm{UFC} / \mathrm{mL}$ e $1,5 \times 10^{6} \mathrm{UFC} / \mathrm{mL}$, valores também acima do permitido pela IN 062, corroborando com o encontrado na Propriedade I.

Foram detectados resíduos de antimicrobianos em 6,97\% amostras de leite da Propriedade I e em 9,24\% da Propriedade II. Ribeiro et al. (2009) encontraram somente quatro $(2,7 \%)$ amostras de leite com resíduos, provenientes de leite de bovinos criados em sistema orgânico no interior do Estado de São Paulo. A detecção de resíduos está em desacordo com as normas instituídas pelas IN 062 e IN 064 do MAPA (BRASIL, 2011; 2008) que proíbem a presença de qualquer resíduo de antimicrobiano em leite produzido em sistema convencional ou orgânico.

Os níveis celulares acima dos limites estabelecidos no Brasil e a presença de amostras positivas para resíduos de antimicrobianos revelaram problemas de qualidade do leite orgânico produzido nas propriedades amostradas e a necessidade do investimento em ações de controle das mastites sem o uso de antimicrobianos. Estes resultados contrariam os conceitos da produção orgânica e revelam riscos para a saúde pública.

\section{AGRADECIMENTOS}

À Fundação de Amparo à Pesquisa do Estado de São Paulo (FAPESP) pela concessão de Bolsa de Doutorado (Projeto 08/51040-4).

\section{REFERÊNCIAS}

BRASIL. Ministério da Agricultura, Pecuária e Abastecimento. Instrução Normativa n.062 de 29 de dezembro 2011. Aprova os Regulamentos técnicos de produção, identidade e qualidade do leite tipo $A$, do leite tipo $B$, do leite tipo $C$, do leite pasteurizado e do leite cru refrigerado e o regulamento técnico da coleta do leite cru refrigerado e seu transporte a granel. Brasília, 2011. Disponível em: <http:/ / www. agricultura.gov.br/Instrução Normativa 62>. Acesso em: 17 set. 2012.

BRASIL. Ministério da Agricultura, Pecuária e Abastecimento. Instrução Normativa n.064 de 18 de dezembro de 2008. Aprova o Regulamento técnico para os sistemas orgânicos de produção animal e vegetal. Brasília, 2008. Disponível em <http:/ / www.agricultura.gov.br/Instrução Normativa 64>. Acesso em: 18 fev. 2010.

CAMPIOLO F.A.; SILVA F.F. Orgânicos: garantia de saúde e possibilidade de sucesso econômico para o Brasil. Revista Cesumar, v.11, p.145-165, 2006.

CAMPOS, E.P. Qualidade microbiológica, físico-química e pesquisa de resíduos de antibióticos e pesticidas no leite bovino produzido pelo sistema convencional e pelo sistema orgânico. 2004. 58p. Dissertação (Mestrado em Medicina Veterinária) - Faculdade de Medicina Veterinária e Zootecnia, , Universidade Estadual Paulista, Botucatu, SP,2004

COMERON, E.; ROMERO, L.; CUATRIN, A.; MACIEL, M. El efecto racial e genético. In: TAVERNA, M. Manual de referencias técnicas para el logro de leche de calidad. Santa Fe: INTA-Rafaela, 2005. p.119-134.

ECOCERT BRASIL. Certificações. Disponivel em: <www. ecocert.com.br/projetos.php>.. Acesso em:30 jan. 2011.

ELLIS, K.A.; INNOCENT, G.T.; MIHM, M.; CRIPPS, P.; McLEAN, W.G.; HOWARD, C.V.; GROVE-WHITE, D. Dairy cow clean lines and milk quality on organic and conventional farms in the UK. Journal of Dairy Research, v.74, p.302-310, 2007.

FERNANDEZ, V.N.V.; ZANELA, M.B.; PINTO, A.T.; RIBEIRO, M.E.R. Qualidade do leite ecológico produzido em uma unidade de produção do Rio Grande do Sul. Acta Scientiae Veterinariae, v.37, p.45-48, 2009.

HAMILTON, C.; EMANUELSON, U.; FORSLUND, K.; HANSSON, I.; EKMAN, T. Mastitis and related management factors in certified organic dairy herds in Sweden. Acta Veterinaria Scandinavica, v.48, p.1-7, 2006.

IBD - Instituto Biodinâmico (Brasil). Certificações. Disponível em: <http:/ /www.ibd.com.br>. Acesso em: 30 jan. 2011.

IBGE - Instituto Brasileiro de Geografia e Estatística. Produção pecuária municipal. Rio de Janeiro: IBGE, 2010. v.38, p.1-61. 
IFOAM. - International Federation of Organic Agriculture Moviments. The world of organic agriculture: statistics and emerging trends: 2003. YUSSEFI, M.; WILLER, H. (Ed.). Bonn: IFOAM, 2003. Disponível em: <http:/ / www. ifoam.org>. Acesso em: 12 nov. 2009.

IFOAM. - International Federation of Organic Agriculture Moviments. The world of organic agriculture : statistics and emerging trends:2006. WILLER, H.; YUSSEFI, M. (Ed.). 8.ed. Bonn : IFOAM, 2006. 186p.

IFOAM - International Federation of Organic Agriculture Moviments. The world of organic agriculture : statistics and emerging trends :2009. Eds. H. Willer, L. Kilaher. Bonn : IFOAM, 2009. 299p.

LANGONI, H.; SAKIYAMA, D.T.P.; GUIMARÃES, F.F.; MENOZZI, B.D.; SILVA, R.C. Aspectos citológicos e microbiológicos do leite em propriedades no sistema orgânico de produção. Pesquisa Veterinária Brasileira, v.29, p.881-886, 2009.

RADOSTITS, O.M.; GAY, C.C.; HINCHCLIFF, K.W.; CONSTABLE, P.D. Veterinary Medicine: A textbook of the disease of cattle, horses, sheep, pigs and goats. New York: Saunders Elsevier, 2007. 2156p.
RIBEIRO, M.G.; GERALDO, J.S.; LANGONI, H.; LARA, G.H.B.; SIQUEIRA, A.K.; SALERNO, T.; FERNANDES, M.C. Microrganismos patogênicos, celularidade e resíduos de antimicrobianos no leite produzido no sistema orgânico. Pesquisa Veterinária Brasileira, v.29, p.52-58, 2009.

ROESCH, M.; DOHERR, M.G.; SCHAREN, W.; SCHALLIBAUM, M.; BLUM, J.W. Subclinical mastitis in dairy cows in Swiss organic and conventional production systems. Journal of Dairy Research, v.74, p.86-92, 2007.

SCHALM, O.W.; CARROL, E.J.; JAIN, N.C. Bovine Mastitis. Philadelphia: Lea and Febiger, 1971. 360p.

TOLEDO, P.; ANDRÉN, A.; BJORCK, L. Composition of raw milk from sustainable production systems. International Dairy Journal, v.12, p.75-80, 2002.

WELLER, R.F.; BOWLING, P.J. Health status of dairy herds in organic farming. Veterinary Record, v.146, p.8081, 2000.

Recebido em: 25/1/11

Aceito em: $4 / 7 / 12$ 